\title{
Currarino syndrome: typical images of a rare condition
}

\author{
D. Leonard • R. Pendlimari • D. W. Larson • \\ E. J. Dozois
}

Received: 20 April 2010/Accepted: 6 May 2010/Published online: 26 May 2010

(C) Springer-Verlag 2010

Currarino syndrome (CS) is a rare autosomal dominant disorder with variable phenotypes including sacral abnormalities, genitourinary malformations, anorectal and gynecological anomalies and presacral tumors. In addition to other abnormalities, more than one presacral lesion may coexist in the same patient. The following radiographic images, although infrequently seen, are typical for CS and should alert surgeons seeing patients for presacral lesions about the possible presence of this syndrome (Figs. 1, 2, 3, 4, 5).

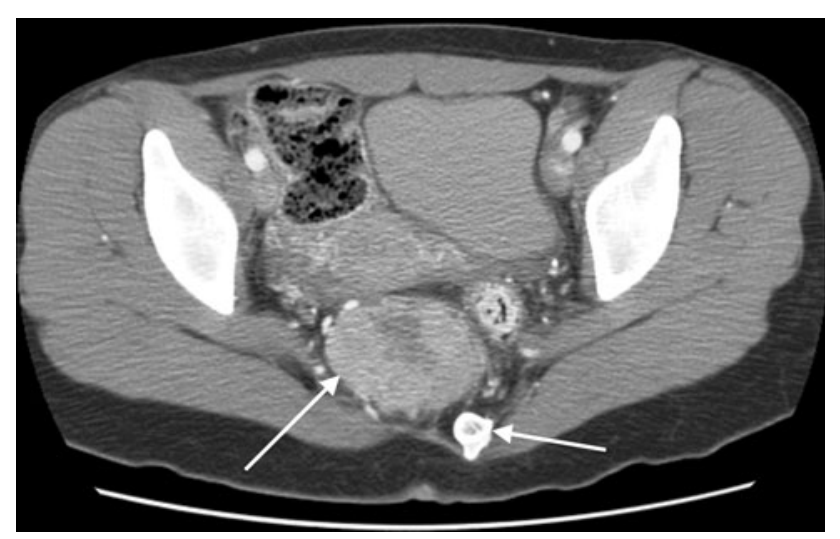

Fig. 1 A 22-year-old woman (patient A), who presented with pelvic pain and constipation, underwent a contrast-enhanced pelvic CT-scan. This selected axial image shows a heterogeneous enhancing presacral mass (long arrow) that lateralizes the rectum and is associated with an asymmetrical bony sacrum (short arrow)

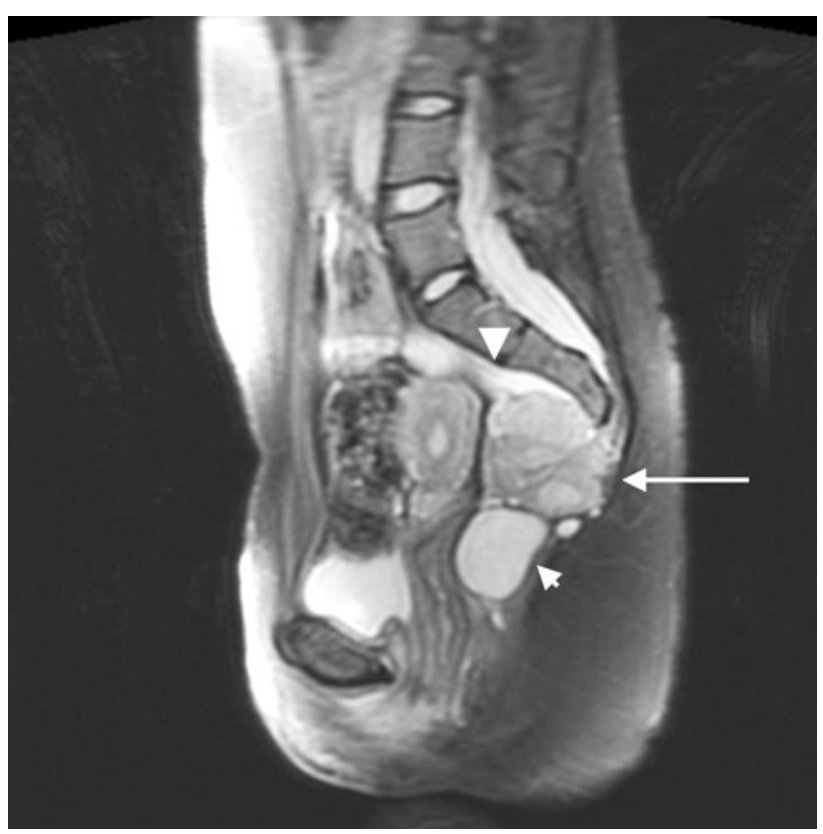

Fig. 2 Patient A underwent an MRI of the pelvis (sagittal T2-weighted image) with gadolinium showing a heterogenous soft tissue mass along the anterior margin of the second and third sacral segments (teratoma) (arrow). Immediately adjacent to the cranial and caudal aspects of this mass, there are two cystic lesions representing an anterior meningocele (arrow head)

D. Leonard · R. Pendlimari · D. W. Larson · E. J. Dozois ( $\square)$

Division of Colon and Rectal Surgery,

Mayo Clinic, Gonda 9 South, 200 First Street SW,

Rochester, MN 55905, USA

e-mail: Dozois.eric@mayo.edu 


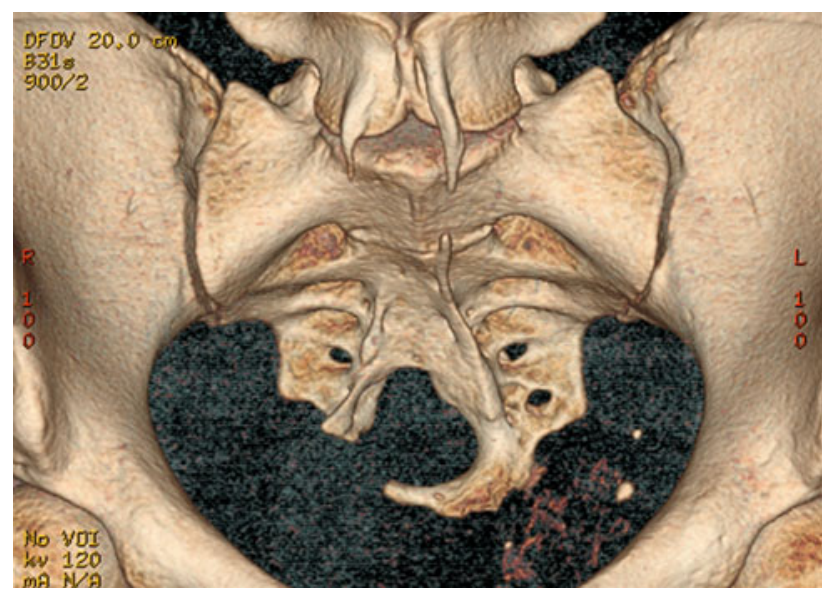

Fig. 3 For patient A, a virtual 3D reconstruction of the bony pelvis from her pelvic CT-scan showed the classical "scimitar-shaped" sacral anomaly found in CS

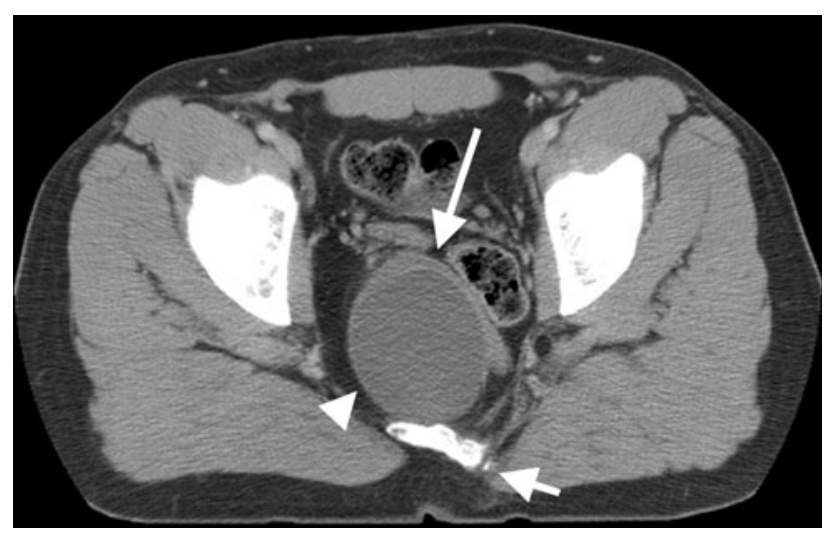

Fig. 4 A contrast-enhanced pelvic CT-scan of a 32-year-old man (patient B) who presented with progressive pelvic and "tailbone" pain. Axial image shows the dual pathology of a presacral dermoid cyst (arrow head) in close relationship with a meningocele (arrow). The sacrum shows anomalous anatomy (short arrow)

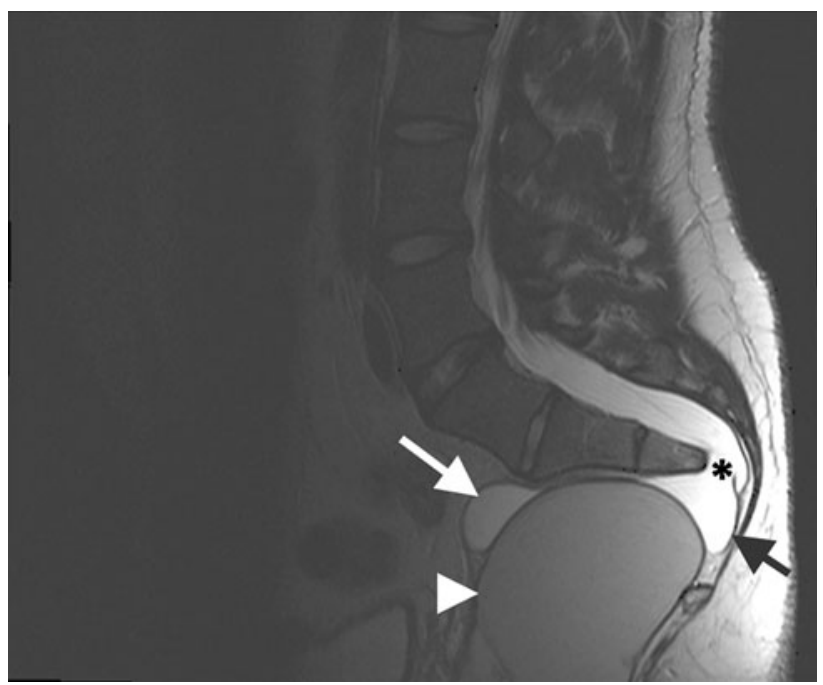

Fig. 5 Patient B underwent MRI of the abdomen and pelvis with gadolinium. This sagittal T2-weighted image shows a dermoid cyst (arrow head) surrounded by a meningocele (black and white arrow). The spinal origin of the meningocele is clearly visible (asterisk) 